\section{SHANGHAI JAZZ MUSIC FROM 1930 TO 1949}

\author{
Andrew Toe Yuan Loong \\ Universiti Malaysia Sarawak

\section{Thia Sock Siang} \\ Universiti Malaysia Sarawak
}

Corresponding Author ssthia@unimas.my
Jazz music emerged in Shanghai, China between the late 1920s and early 1930s. This paper documented and analysed Shanghai jazz music that was recorded from 1930 to 1949. Shanghai jazz music recorded and performed within this period was selected through stratified random sampling technique. All samples were analysed in terms of melody, harmony, rhythm and form. The results showed that Western diatonic scale was apparent in the melodies, instead of the usual Chinese pentatonic scale; primary chords were prevalent with minimal use of secondary chords in the harmony; the "oom-pah" rhythm in duple meter was most widely utilized; and the musical form has evolved from the earlier through-composed song form to the later "AABA" form. In conclusion, this research characterised Shanghai jazz music that were recorded between 1930 to 1949 . It served to elevate the identity of this music and to prompt further research into Shanghai jazz music spanning from 1950s until present time.

Keywords: Shanghai; jazz music; music analysis; music identity 


\section{INTRODUCTION}

"In its transformation from fishing village to bustling trading port and now business centre, Shanghai has survived wars, foreign takeovers, communism and the Cultural Revolution to emerge as China's leading city" (Dorai, 2008).

Shanghai is a city located in the east coast of China, and its as a trading port can be traced back to around the 10th to 13th century during the Song dynasty. By the early 20th century, Shanghai was already leading China in wealth, business, industry, finance, arts as well as culture. Famously known as the 'Paradise for Adventurers' and 'Paris of the East', Shanghai is christened as the world's fifth largest city in terms of population since the 1930s. In fact, according to the Demographia World Urban Areas, 10th Annual Edition revised at May 2014, Shanghai's population is estimated to be 22,650,000, and is the 6th largest urban Areas in the World (Koh and Jaques, 2006).

It has been noted that Shanghai's foray as an international metropolis began with the arrival of the British consul in November 1843. Although Britain took the first step in controlling Shanghai politically and commercially, it was not the only foreign power vesting interests in Shanghai; in 1849, the French acquired similar concessions from the Chinese government, while the American claimed a settlement of their own in Shanghai in 1854 (Wei, 1993).

From 1930 to 1949, there are many people of different nationalities residing in Shanghai, besides the Chinese. Thus, a diverse type of music can be found in Shanghai (Cheung, 2012; Christian, 2004; Edmunds and Yang, 2012; Ho, 2012; Riggs, 1991; Tang, 2004; Atkins, 1999). However, the music can be further divided into two categories: Chinese music originating in China, and Western music originates from foreign countries. Cheung mentioned that both Chinese and Western music developed separately, but were connected with each other in Shanghai. In addition, Chinese music in Shanghai can be further distinguished into smaller but specific categories: instrumental, vocal, and opera.

The term Shanghai jazz music is used in this paper, as the term was used during the first discussion related to Chinese jazz music (Hip Deep: Andrew Jones on the Story of Shanghai Jazz n.d.). Shanghai jazz music is also known through different resources as Chinese popular music, liú xíng yīn yuè (流行音樂) or liú xíng gē qǔ (流行歌曲) (Lau 2008); modern Chinese pop music (Field 2010); modern songs or shí dài qǔ (時代曲); Chinese popular music; yellow music, huáng sè yīn yuè (黃色音樂); popular Chinese songs (Hip Deep: Andrew Jones on the Story of Shanghai Jazz, n.d.); and jazz piece in China (Marlow, 2011). 
Although jazz music started in Shanghai in the the late 1910s (Marlow, 2011) or 1920s (Field 2010), it was not until 1927 when the first Shanghai jazz music, máo mao yǔ(毛 毛雨) composed by a Chinese composer, Li Jinhui, appeared (Siu and Ku, 2009). Moreover, productions of these recordings started to appear from the 1930s. 1949 marked the year where the industry of Shanghai jazz music was relocated to Hong Kong and subsequently evolved into a different type of music (Lau, 2008). This was the time when the Chinese Communist Party, who gained complete political control over China, banned the production of Shanghai jazz music.

Since the emergence of Shanghai jazz music from the 1920s until today, there are not many analytical studies done to justify the identity of this genre. Apart from that, according to the research done by Jones (as cited by Atkins in 2003), there are "few textual records and almost no oral histories of this period that can be relied on". Furthermore, other than briefly describing Shanghai Jazz music as "a hybrid genre of American jazz, Hollywood film music, and Chinese folk music" (Jones, 2001), or "popular music modelled on big band jazz style", melodies based on pentatonic scales and lyrics "sung in Mandarin Chinese" (Lau, 2008), or other sources citing similar facts, there are limited musical details that can be found regarding this genre.

This paper focuses only on Chinese jazz music which was composed and arranged by the Chinese people, and performed or recorded in Shanghai from 1930 to 1949. The four musical elements of the Shanghai jazz music that were analysed are the melody, harmony, rhythm and form.

\section{BACKGROUND}

According to Kennedy (2007), jazz is a term that came into general use around 1913 till 1915. It is a genre that started to develop in the late 19th century in the Southern States of the United States of America and came into prominence at the turn of the century in New Orleans. Field (2010) briefly describes jazz as a form of danceable popular music with elements such as syncopated rhythms, improvisations and catchy lyrics. Jazz consists of various elements taken from various places such as the rhythms of West Africa, the harmony of Europe, and the 'gospel' singing from America. Kamien (2011) further elaborates that the influence of West Africa includes the importance of improvisation, drumming, percussive sounds, complex rhythms, and a feature known as call and response. Call and response take place when a phrase of a voice or instrument is answered by another voice, instrument or group. Apart from 'gospel' singing, there are also work songs, spirituals, dances and the band tradition by the influence of America. 
According to Megill and Demory (1989), the synthesis of jazz started over 500 years from now, when the first Black slaves arrived in Europe from West Africa, transported by Portuguese explorers. They also stated that despite being influenced by music of various countries, jazz has successfully earned itself a place within the American identity.

Looking over the historical span of this music, jazz has evolved into a rich variety of smaller groups called subgenres. Organising these subgenres into a more orderly manner, the blues and piano styles like ragtime, stride and boogie woogie, are known as the foundation or predecessor of jazz (Megill and Demory, 1989). Wright and Simms (2010) cited that these early styles started to exist around 1900 in America, while the New Orleans Jazz (or Dixieland), swing, and bebop flourished before the 1950s. For other jazz subgenres after 1950, the range of developments became wider than ever, and these innovations, including cool jazz, free jazz, and jazz rock, became the prominent subgenres as each has its own distinctive directions. Apart from that, Kamien (2011) stated that jazz after 1950 was meant more for listening than for dancing as suggested by Andrew Field. Although jazz music is very diverse and complex, there are several general characteristics of jazz that can be summarised. Here, only elements of jazz created before 1950 will be discussed.

First, from the aspect of instrumentation, jazz is normally played by a small group called combo (which consists of three to eight players), or a large group named big band (with ten to fifteen players). In a jazz ensemble, a group known as rhythm section comprises of piano, double bass, percussion and sometimes banjo or guitar. Norman (1998) states that the essential functions of this ensemble are to keep time, realise harmony or chords, and execute the rhythmic patterns of specific music styles. In addition, Kamien (2011) emphasises that jazz is preferably played by brass, woodwind, and percussion as opposed to the bowed string family in classical music.

Secondly, as for tone colour, in classical music, each instrument has its own "ideal" sound or tone. However, jazz aims for individuality of personal tone. Apart from that, instrument players often produce various peculiar sounds through creative playing techniques as they attempt to imitate the vocal sound of singers. In jazz, musician employs expressions including growls, bends and slurs as personal interpretation towards music (Tanner et al., 2009). Kamien (2011) opines that distinguishing between the sounds produced by two jazz trumpet players is easier than between two classical trumpeters. 
Thirdly, jazz typically contains improvisation that leads to freshness and spontaneity in music. According to Kamien (2011), improvisations may be based on either melody or harmony. Improvisations based on melody happens when the player embellishes, changes the pitches and rhythms of an original melody. For the second method, improvisers create or improvise melodies over a series of repeated harmonic pattern.

Finally, from the perspective of rhythm, there are several distinctive features which can be found. Two of the general ones as cited by Kamien (2011) are syncopation and swing. Syncopation occurs when accents are played on the weak beat of music. The players who normally provide the beat in jazz are the percussionists as well as bassists. According to Tanner et al., (2009), the frequent use of syncopation in jazz music has made it an identifying characteristic in this genre, and that syncopations also determine how much swing a jazz music has. As stated by Kamien (2011), the feeling of swing can be achieved through playing a series of notes unevenly. A simple example of giving a swing feel is to play two equal quavers unequally, such as giving the second quaver note a shorter time value than the first. Apart from the above, Megill and Demory (1989) also gave an additional rhythmic feature of jazz which is known as layback. Layback can be acquired when musicians intentionally delay notes so that they are slightly behind the beat in the music. This feature which is not so often found in jazz music can create the impression of relaxation in a piece of music.

\section{LITERATURE REVIEW}

According to Field (2010), jazz came into Shanghai in the 1920s. Davis (2009) added that the period Shanghai was encountering jazz was known as the 'Jazz Age'. In Andrew Jones on The Story (n.d.), Jones commented that the Chinese jazz age is the era when modern Chinese pop music started to "develop out of the melting pot of Shanghai". According to Field (2010), "Jazz Age" (1918-1929) is a term coined by an American writer F. Scott Fitzgerald to denote the 1920s. Apart from that, Shaw (as cited in Field 2010) claimed that the Jazz Age can be related to a period when jazz rises as a form of popular music.

As music and dances in jazz were of the Western culture, which has never set foot in Shanghai before the 1920s, the local Chinese responded to jazz with a mixture feeling of excitement and fear. While the older generations frowned upon the culture of jazz due to morality issues, Chinese youths easily adapted to these practices into their lifestyle (Field, 2010). John Pal in his memoir Shanghai Saga (as cited in Field, 2010) described the influence of jazz towards Shanghai as "turning lazy old opium smokers into spry jazz maniacs raring to go". 
Apart from changing the nightlife of Shanghai, jazz also diminishes the boundaries between foreigners or expatriates and local people (Field, 2010). During the early 1920s, Westerners in Shanghai began to appoint jazz orchestras into their establishments. Jazz musicians began to appear in places such as hotels, cafes and clubs to provide entertainment to the public through performing jazz music.

Field (2010) states that jazz was brought to Shanghai through the steamship, as well as gramophone records. However, Jones (as cited in Atkins, 2003) comments that gramophone records were only one of the factors. Instead, "the emergence of jazz music in China was a direct result of colonial commerce in the treaty-port milieu". To elaborate in another manner, jazz music entered China due to colonialism, and Shanghai, which was part of China, was turned into a treaty port. As mentioned by Cheung (2008), colonialism and treaty port in Shanghai can be related to the incident of Opium War.

Preceding the Opium War and colonialism, the Chinese empire (Qing dynasty) only allowed one port for foreign trading, which was located at Canton (Guangzhou) in southern China (Koh and Jaques, 2006). By 1800, the British were importing opium grown and processed in India in exchange for tea, silk and porcelain from China. The addiction to opium within the Chinese community caused the Qing emperor to ban the aforesaid substance. In 1839, an act of destroying an enormous amount of British opium took place in Canton, and as a result, the British demanded for compensation and more access to the coastal ports in China. However, the demand was turn down by the Chinese, which turned into the Opium War in 1842. As the Chinese were unable to withstand the British forces, the Treaty of Nanking was signed at the same year. Under the terms of the treaty, Shanghai, along with another four ports, was opened, in addition to the cession of Hong Kong to the British. The privilege won by British soon encouraged other countries, such as France and America, to gain their access in Shanghai for self-benefits. Soon enough, each foreign power created their respective settlement in Shanghai (Koh and Jaques, 2006).

\section{METHODOLOGY}

This paper, exploratory in nature, utilised qualitative method to collect data in order to document and analyse the general characteristic of Shanghai Jazz Music recorded from 1930 to 1949 (Kumar, 2005). The population of this research constitutes of Chinese music with jazz elements composed and arranged by Chinese composers in Shanghai, and recorded or performed between 1930 and 1949. However, the exact number of population remained unknown due to the limited availability of documented resources. Moreover, ambiguity arises in the labelling given to Shanghai jazz music. 
For example, in discographies, Shanghai jazz music is grouped together with mass song and children song as Shanghai pop songs or shàng hăi lăo gē (上海老歌) which literally means Shanghai old songs. This can be found in the discography of Zhou (2008), which contains 392 tracks.

In this research, stratified random sampling technique was employed in order to eliminate possible bias in selecting sample (Ahmad and Usop, 2011). Stratified random sampling involves dividing a research with large population size into subgroups or sampling frame (strata) based on variables, and then taking simple random samples from each subgroup. Here, in order to identify the stratification variable as time in the unit of years for the analysis in Shanghai jazz music, each stratum contains a period of five years. The rationale behind using such method is that the style of jazz "never remained stable for long" and is a "musical phenomenon always in progress" (Wright and Simms, 2010). Moreover, instead of simply generalising Shanghai jazz music from a period of more than 20 years, a more thorough and detailed analysis will be achieved if the samples are categorised into smaller time frame. Hence, the research plan on the analysis of Shanghai jazz music can be summarised as shown in Table 1.

Table 1: The research plan in analysing the Shanghai jazz music

\begin{tabular}{|c|c|}
\hline Strata (Years) & Sample Size (Number of Music Samples) \\
\hline $1927-1934$ & $\leq 10$ \\
\hline $1935-1939$ & $\leq 10$ \\
\hline $1940-1944$ & $\leq 10$ \\
\hline $1945-1949$ & $\leq 10$ \\
\hline
\end{tabular}

\section{RESULTS AND FINDINGS}

All 40 music samples selected were transcribed before they were being analysed. The transcriptions were produced in the format of condensed scores with the main melody, melodic accompaniment/counter melody/filler (which are significant), harmony and bass. Each sample is not being individually emphasised in detail here. Rather, an overall elaboration is given to the music drawn from each sampling frame. The general characteristics were identified based on the analysis performed on the music samples in four musical aspects, namely the melody, harmony, rhythm and form of the music. 


\subsection{Melody}

As mentioned by Lau (2008), from the aspect of melodic scale, Shanghai jazz music is in pentatonic scale. According to Giskin and Walsh (2001), the pentatonic scale of Chinese music is a five-tone scale that sounds like a western major scale, but without the fourth and seventh degree. However, the appearance of Chinese pentatonic scale is not visible in all 40 music samples based on analyses through all transcriptions. Through stratified random sampling technique, it is found that the usage of the Western diatonic scale is present in all four of the sampling frames. In the first two strata, the numbers of samples that are in Western diatonic scale are and 6 respectively. Interestingly, the scale of Chinese pentatonic scale is almost absent starting from the third sampling frame (or 1940) onwards, and is replaced by the Western diatonic scale. In the third stratum, it is found out that none of the selected samples is in Chinese pentatonic scale. Lastly, in the fourth stratum (the period of 1945 to 1949), only one of the sample, which is děng zhe nǐ huí lái 等著你回來 recorded in 1948, sung by the Chinese vocalist bái guāng 白光, is in Bb pentatonic scale.

Besides, phrase structure of Shanghai jazz music evolves according to the time period which is from 1930 to 1949 . All ten samples of the first sampling frame, 1930 to 1934 , consists of irregular phrases in its melody. However, the structure of the music changes and tends to be regular in its phrasing starting from 1935. Noticeably, majority of the music in the final stratum, 1945 to 1949 , is in regular phrase whereby only yè shàng hăi 夜上海 and wǒ xiăng wàng le nǐ 我想忘了你, both recorded in 1946, have irregular phrases.

\subsection{Harmony}

The analyses showed that the music samples selected in the first stratum, 1930 to 1934 , is mainly accompanied by the three primary chords which are I, IV and V chords regardless of its position Nonetheless, several of the recordings have minimal use of secondary chords (II, III and VI) besides just primary chords.

In the second period, 1935 to 1939 , based on the ten selected samples by the researcher, four of the samples have only primary chords throughout the music, while another four has some additional secondary chords in its harmony. Interestingly, from this period onwards, there are incorporations of altered chords, such as borrowed chords and secondary dominants.

As for the third and fourth period, from 1940 and onwards, it is found that all of the selected samples have used various chords, including primary, secondary and altered chords in its harmony. Obviously, through analysis, Shanghai jazz music has changed gradually in terms of its harmony through time, starting from merely simple primary 
chords as accompaniment to rich and sophisticated harmonic progression at the late period of Shanghai jazz era.

\subsection{Rhythm}

Generally, there are three different types of meters which can be found in Shanghai jazz music, which are the duple, triple and quadruple meter. Nevertheless, this genre has a rich variety of rhythmic features in it. Through analysis, it is found out that the most popular rhythm which can be found since the first sampling frame of the research, 1930 to 1934, is the "oom-pah" rhythm in duple meter. Apart from the "oom-pah" duple rhythm, the music in triple meter too has made its appearance in Shanghai Jazz during this time. Through listening, the music that is in triple meter in this period is in ballad style. One such example is bā jiāo yè shàng shī 芭蕉葉上詩 which is sung by wáng rén měi 王人美 and recorded in 1931.

In the second period, 1935 - 1939, the tango style which is in quadruple meter has started to be heard in Shanghai jazz, reflecting the rise of the tango dance trend of the people living in Shanghai during that time. Besides, the waltz in triple time too has started to exist in this period.

In the sampling frame of 1945 to 1949 , the "oom-pah" rhythm has lost its favour in Shanghai jazz music, and this could be due to the rise of popularity of the dance rhythm which are mostly in quadruple meter. Example of these dance styles are the Tango and Rumba. An example of music in rumba style (xiāng gé lí lā 香格里拉) is shown in Figure 16. Besides that, the swing style, which was at its peak in the Western world during this period, has also begun to emerge in Shanghai as a response to the latest convention of music.

\subsection{Form}

The form of Shanghai jazz music shows an interesting evolution from the earliest to the latest period. To come up with a simple deduction, the form of this music in the early period tends to be through-composed song form, while in the later period, the music has taken the form of AABA, or also known as the thirty-two-bar popular song form (because each phrase is eight bars long, summing up to 32 bars in length). According to Wright and Simms (2010), through-composed is a form in which new musical ideas are being introduced in every line or stanza and repetition never occurs, as opposed to strophic form. As for AABA form, the first a phrase is being played twice, then followed by a contrasting $b$ phrase and finally returning with the a phrase (Kamien 2011). 
Nevertheless, not all Shanghai Jazz music in AABA form is in the conventional thirtytwo bars form as several of the recordings selected are in irregular phrases. For example, in yè shàng hăi 夜上海, although the $A$ phrase is eight bars long, the contrasting $B$ section is irregular in phrase, thus being twelve bars long. In whole, the AABA form of this music is thirty-six bars in length.

Apart from the two types of form as mentioned, there are also other uncommon forms that exist in Shanghai jazz music. In méi guī méi guī wǒ ài nǐ 玫瑰玫瑰我愛你, as opposed to the former two examples, this song takes the AABAA form, with $A$ being sixteen bars long whereas $B$ in seventeen bars length.

In addition, there are also other less frequently used forms in Shanghai jazz music such as three-part song form ( $\mathrm{ABA})$ and $\mathrm{ABB}$ in xiăo tiān shǐ 小天使 and mài huā nŭ 賣花女 respectively.

\section{CONCLUSION}

The documentation and characterization of Shanghai jazz music is crucial in preserving the identity of this music genre. This paper discovered that all 40 of the recordings have at least one vocal solo in it. In other words, there was no music of instrumental jazz that was found in Shanghai from 1930 to 1949 . This genre is actually more specifically labelled under the category of song instead of just the broader term of music. From the instrumental aspect, it has been noted that a significant number of the selected samples actually contains the unique feature of unison playing between the vocal and other instruments, in which instruments such as the flute or violin playing the same melody as sung by the main vocalist at the same time.

\section{REFERENCES}

1. Ahmad, R., \& Usop, H. (2011). Conducting Research in Social Sciences, Humanities, Economics and Management Studies: A Practical Guide. Sarawak: RS Group Publishing House.

2. Atkins, E. T. (2003). Jazz Planet. USA: University Press of Mississippi.

3. Cheung, J. H. Y. (2008). Chinese Music and Translated Modernity in Shanghai, 1918-1937. USA: University of Michigan.

4. Cheung, J. H. Y. (2012). Divide and Connections in Chinese Musical Modernity: Cases of Musical Networks Emerging in Colonial Shanghai, 19191937. Twentieth-Century China, 37(1), 30-49.

5. Christian, U. (2004). Cultural Accommodation and Exchange in the Refugee Experience: A German-Jewish Musician in Shanghai. Ethnomusicology Forum, 13(1), 119-151. 
6. Davis, E. L. (2009). Encyclopedia of Contemporary Chinese Culture. USA: Taylor \& Francis.

7. Dorai, F. (2008). Insight Guides Shanghai (2nd ed.). Singapore: APA Publications.

8. Edmunds, N., \& Yang, H. L. (2012). The Shanghai Conservatory, Chinese Musical Life, and the Russian Diaspora, 1927-1949. Twentieth-Century China, 37(1), 73-95.

9. Field, A. D. (2010). Shanghai's Dancing World: Cabaret Culture and Urban Politics, 1919-1954. Hong Kong: The Chinese University Press.

10. Giskin, H., \& Walsh, B. S. (2001). An introduction to Chinese culture through the family. USA: Suny Press.

11. Hip Deep: Andrew Jones on the Story of Shanghai Jazz. (n.d.). Retrieved October 12, 2014, from http://www. afropop.org/wp/2415/andrew-jones-on-thestory-of-shanghai-jazz/

12. Ho, W. C. (2012). Music Education in Shanghai from 1895 to 1945: The Cultural Politics of Singing. Music Education Research, 14(2), 187-207.

13. Jones, A. F. (2001). Yellow Music: Media Culture and Colonial Modernity in the Chinese Jazz Age. USA: Duke University Press.

14. Kamien, R. (2011). Music: An Appreciation (11th ed.). New York: McGraw-Hill.

15. Kennedy, M. (Ed.) (2007) The Concise Oxford Dictionary of Music (5th ed.). USA: OUP.

16. Koh, B., \& Jaques, Z. (2006). Shanghai Chic. Singapore: Archipelago Press.

17. Kumar, R. (2005). Research Methodology (2nd ed.). London: SAGE.

18. Lau, F. (2008). Music in China, Experiencing Music, Expressing Culture. USA: OUP.

19. Marlow, E. (2011). Jazz. Global Music, from http://www.chambermusic.org/pdf/12SOGMI.pdf

20. Megill, D. D., \& Demory, R. S. (1989). Introduction to Jazz History (2nd ed.). USA: Prentice-Hall.

21. Norman, D. (1998). Jazz Arranging. USA: Scarecrow Press.

22. Riggs, P. (1991). Up from Underground: Sound Technologies, Independent Musicianship, and Cultural Change in China and the Soviet Union. Popular Music and Society, 15(1), 1-23.

23. Siu, H. F., \& Ku, A. S. (2009). Hong Kong Mobile: Making a Global Population, from

https://books.google.com.my/books?id=LTr9AAAAQBAJ\&printsec=frontcover\# $\mathrm{v}=$ onepage $\& q \& \mathrm{f}=$ false

24. Tang, Y. T. (2004). Reconstructing the Vanished Musical Life of the Shanghai Jewish Diaspora: A Report. Ethnomusicology Forum, 13(1), 101-118.

25. Tanner, P., Megill, D. W., \& Gerow, M. (2009). Jazz (11th ed.). USA Mc GrawHill. 
26. Taylor Atkins, E. (1999). Jammin' on the Jazz Frontier: The Japanese Jazz Community in Interwar Shanghai. Japanese Studies, 19(1), 5-16.

27. Wei, B. P. T. (1993). Old Shanghai. Hong Kong: OU.

28. Wright, C., \& Simms, B. (2010). Music in Western Civilization. Belmont: Thomson Schirmer. 